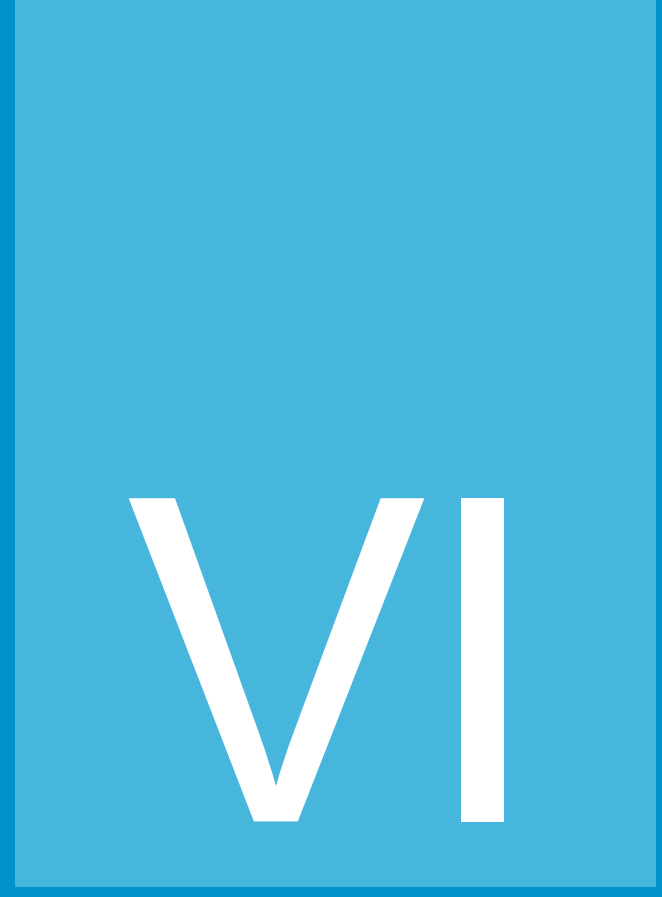

\title{
LAS ESCUELAS DE LOS PROFETAS
}

\section{The schools of the prophets}

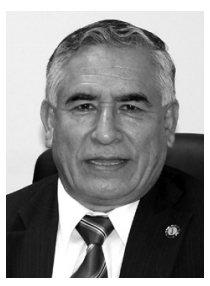

\section{Francisco Quinteros del Águila}

Doctor en Teología por la Universidad Peruana Unión. Se desempeñó como decano de la Facultad de Teología y actualmente es director general de la UPeU, con sede en Tarapoto. Ha escrito numerosos artículos y es profesor visitante a nivel nacional e internacional. 


\section{Resumen}

El autor explora la relación entre la educación actual y las escuelas de los profetas como modelo educativo. Para ello se parte de un estudio histórico para identificar las escuelas de los profetas en la Biblia y en los escritos de Elena de White. Este artículo propone una reflexión en torno a la educación cristiana desde una plataforma bíblica, en la cual se contempla un espíritu de devoción y cristianismo profundo de parte de los docentes; la relación del estudio y el trabajo como una característica distintiva del estudiante, así como una atención tutorial personalizada; lo que equivale a un modelo educativo vigente que bien harían los maestros y administradores en imitar.

Palabras clave: Filosofía de la educación cristiana, modelos educativos, pedagogía, educación adventista.

\section{Abstract}

The author explores the relationship between current education and schools of the prophets as an educational model. This is part of a historical study to identify the schools of the prophets in the Bible and in the writings of Ellen White. This paper proposes a reflection on christian education from a biblical platform, which provides for a spirit of deep christian devotion and the teachers, the relationship of the study and work as a distinctive feature of the student as well as personalized tutorial attention, which is equivalent to an educational model that well would force teachers and administrators to imitate.

Keywords: Philosophy of christian education, educational models, pedagogy, adventist education 


\section{Introducción}

La educación adventista avanza, crece y se fortalece año tras año. Según datos oficiales en el 2011 la iglesia adventista, a nivel mundial, administró la educación de 1758737 alumnos y recibió en sus filas, por medio del bautismo, a 50752 estudiantes (Yearbook, 2012). Solo en el territorio de la División Sudamericana ${ }^{1}$, durante el 2012, la población estudiantil en las aulas adventistas sumó 275461 y de ellos, 10819 decidieron abrazar la fe cristiana adventista.

Sin embargo, sería interesante formularnos periódicamente algunas preguntas clave para medir el desarrollo real de la educación adventista en todas las áreas de la misma: ¿Cuáles serían los indicadores del verdadero éxito de la educación adventista? ¿Qué modelo educativo se sigue? ¿Cuán bíblicamente sólidos y denominacionales son nuestros currículos académicos?

A la luz de las Sagradas Escrituras y los escritos de Elena de White, una de esas fortalezas y excelente referente puede encontrarse en el modelo de las antiguas 'escuelas de los profetas'.

\section{Definición}

La expresión 'escuela de los profetas' no se halla en la Biblia. No obstante, aparecen otros términos equivalentes tales como 'hijos de los profetas' (1 Reyes 20:35; 2 Reyes 2:3, 5, 7, 15; 4:1, 38; 9:1), 'compañía de profetas' (1 Samuel 10:5, 10; 19:20), y 'los profetas' (1 Reyes 22:10).

Sin embargo, entre los estudiosos de este tema, existe el consenso en el que fueron 'los rabinos judíos' los que acuñaron la frase 'escuela de los profetas' para referirse a "las organizaciones de gentes que vivían en torno y a la sombra de algún profeta desde los tiempos de Samuel" (Diez Macho, 1963); y que los términos 'hijos de los profetas', 'compañía de profetas' y 'los profetas' equivalen en realidad a decir discípulos de los profetas. Históricamente estas expresiones vienen desde la época de los profetas Samuel, Elías y Eliseo, quienes en su momento lideraron aquellas "escuelas de música y religión" (Wolfgramm, 1990).

\section{Ubicación estratégica}

Fueron varias las ciudades en las que llegaron a funcionar aquellas

\footnotetext{
${ }^{1}$ Nota del editor. División Sudamericana es un órgano administrativo de la Asociación General de los adventistas del séptimo día, que está compuesto por 8 países sudamericanos, su sede se encuentra en Brasilia, Brasil.
} 
compañías de profetas. Al parecer, el fenómeno de estas escuelas se inició en la época del profeta Samuel como una corriente educacional durante el siglo $\mathrm{XI}$, a. C., en tiempos del rey David. Aquel movimiento comenzó en la ciudad natal de Samuel, Ramá, también Ilamada Ramataín de Zofim, o simplemente Ramataín (1 Samuel 1:1), situada a unos $14.5 \mathrm{~km}$ al norte de Jerusalén. Fue allí donde este profeta nació, residió y fue sepultado (1 Samuel 1:19; 7:17; 25:1).

Quiriat-jearim fue otra de las ciudades donde se establecieron las 'compañías de profetas'. Estaba ubicada en el territorio de Judá. Conocida porque allí se detuvo el arca de Dios por unos 20 años en tiempos de Samuel (1 Samuel 5:1; 6:19; 7:2). Reconocida también como Quiriat-Baal (Josué $15: 60 ; 18: 14)$ distaba unos $12 \mathrm{~km}$ al oeste de Jerusalén.

Al respecto White (PP, 2005, 463), reafirma lo anterior declarando que "en la época de Samuel habían dos de estas escuelas: una en Ramá, donde vivía el profeta (1 Samuel 7:17; 25:1), y la otra en Quiriat-jearim (1 Samuel 7:2) donde estaba el arca en aquel entonces. Se establecieron otras en tiempos ulteriores".

De acuerdo al relato bíblico, un tercer lugar que contaba con una escuela de los profetas fue Gilgal, (2 Reyes 2:1), conocida también como Galgal, la misma que estaba situada cerca de Jericó y donde acampó el pueblo de Israel después del cruce del río Jordán. Quedaba en el límite norte de Judá. Samuel lo incluyó en su circuito anual para ofrecer sacrificios (1 Samuel 7:16). Fue lugar de culto idolátrico denunciado como sitio perverso (Oseas 4:15; $9: 15 ; 12: 11)$. Asimismo, Betel fue otro de los centros donde floreció un grupo de los profetas (2 Reyes 2:3). Betel era conocida como Luz desde los días de Jacob. Geográficamente quedaba al oeste de Hai, y al sur de Silo a unos 17.5 $\mathrm{km}$ al norte de Jerusalén.

Al parecer, Betel se caracterizaba, entre otras cosas, por el culto idolátrico al becerro, en tiempos de Acab y Jezabel y Jeroboam I, asimismo, fue donde el rey Josías quemó los huesos de los sacerdotes idólatras (1 Reyes 13:1-13) y donde también el profeta Samuel juzgó muchas veces a Israel (1 Samuel 7:16; 10:3).

Jericó, identificada también como la "ciudad de las palmeras", es otra de las ciudades reconocidas como sede de los 'hijos de los profetas' (2 Reyes $2: 4,5,15,18)$. Estaba situada en el valle del Jordán, a unos $8 \mathrm{~km}$ al este del río, a unos $13 \mathrm{~km}$ al norte del Mar Muerto y a unos $24 \mathrm{~km}$ de Jerusalén, en el límite entre Efraín y Benjamín.

Asimismo, no se puede descartar la posibilidad que también en Samaria, capital del Reino del Norte, haya existido una de aquellas compañías de 
profetas, dado que tanto Elías como Eliseo tuvieron allí su residencia habitual y que allí trabajaron esforzadamente para contrarrestar la impiedad propia de esos tiempos (2 Reyes 2:25; 5:9; 6:24, 25, 32).

Cabe resaltar que las ubicaciones de aquellos centros de formación de la antigüedad no se produjeron por mera casualidad, sino en función a los propósitos divinos. Al referirse a una de ellas, Nichol (1980), señala que "la escuela de los profetas de Jericó (2 Reyes 2:4-5), no se estableció allí por accidente. Jericó estaba en un importante camino por el cual iban muchos viajeros de las regiones del otro lado del Jordán. Se detenían en el oasis de Jericó para descansar y alimentarse, y allí podían relacionarse con los alumnos de las escuelas de los profetas para recibir de ellos el mensaje de esperanza y confianza en el Señor que debía llevarse por doquier".

\section{Grandes objetivos}

Son diversos los propósitos que tuvieron aquellos centros de formación religiosa y pedagógica entre los hebreos. En opinión de Walvoord y Zuck (1983), uno de los fines básicos de aquellos centros proféticos era "enseñar a los israelitas la Palabra revelada de Dios". Por otro lado, Wolfgramm (1990), enfatiza que surgieron "para proporcionar un suministro regular de los mensajeros por medio de los cuales Dios habla a su pueblo". Nelson (2000), afirma que se fundaron para "forjar maestros y predicadores que enseñaran e interpretaran la Ley y denunciaran el pecado del pueblo". Nichol (1990), puntualiza que los 'hijos de los profetas' acudían a aquellas aulas de los grandes siervos de Yahvéh con la finalidad de "prepararse para tener una parte en la misma obra de reforma a la que habían sido llamados Elías y Eliseo".

White (PP, 2005, 643), por su parte, indica que los grandes cometidos de aquellas escuelas era formar líderes para la iglesia y para la nación hebrea. Ella sintetizó su criterio señalando que la razón básica de esas escuelas hebreas era "servir de barrera contra la corrupción generalizada, para cuidar del bienestar moral y espiritual de la juventud, y para fomentar la prosperidad futura de la nación supliéndole hombres capacitados para obrar en el temor de Dios como jefes y consejeros".

Sin embargo, el propósito supremo de todo sistema educativo debería ser lograr que cada estudiante retorne a su Creador. White (PP, 2005, 645) es categórica al declarar que "el verdadero propósito de la educación es restaurar la imagen de Dios en el alma". 


\section{Metodología efectiva}

Uno de los indicadores fundamentales que distinguía a aquellas "compañías de profetas" era el marcado énfasis de los hábitos devocionales y espirituales como la piedra angular para lograr una sólida formación espiritual, académica y misionera de los jóvenes estudiantes. Al parecer, el sistema educativo de estas escuelas tomó como punto de partida las revelaciones y los escritos sagrados de entonces. Entre los principales indicadores del proceso educacional, White (PP 2005, 645), asevera que "se fomentaba un espíritu de devoción. No solamente se les decía a los estudiantes que debían orar, sino que se les enseñaba a orar, a aproximarse a su Creador, a ejercer fe en él, a comprender y obedecer las enseñanzas de su Espíritu". De esta forma la vida espiritual y misionera de los estudiantes crecía y se fortalecía a la par que avanzaban en su preparación intelectual.

En este sentido, Nelson (1998), afirma "que para ello, estos (los alumnos) se reunían alrededor de los grandes profetas como Samuel o Elías para adorar y orar juntos, así como para mantener la comunión religiosa e instruir al pueblo (1 Samuel 10.5, 10; 2 Reyes 4.38, 40)". Asimismo, Gaebelein (2009), sugiere que el Señor aprobaba y bendecía esa forma de proceder al describir la conducta de Eliseo: "Vemos al gran hombre de Dios en comunión con los hijos de los profetas. Él va con ellos y cuando están en peligro, el poder de Dios se manifiesta a través de él".

Por otra parte, White (2005), insiste en que la combinación del estudio con el trabajo constituía parte insustituible del currículo a impartirse en aquellos centros del saber. Es decir, además del desarrollo de las respectivas materias de los currículos, y de alcanzar los respectivos niveles de enseñanza requeridos, la cultura hebrea determinaba que "por orden divina, a todo niño se le enseñaba un oficio, aun en el caso de tener que ser educado para el servicio sagrado debía aprender un oficio manual". Obviamente, la práctica de este principio otorgaba a cada joven una gran ventaja por cuanto adquiría mayores posibilidades de desarrollo individual y mejores oportunidades para la vida.

Otra característica de aquellas escuelas era la atención personalizada que los maestros brindaban a sus estudiantes. Así tenemos la evidencia bíblica que algunos de los docentes vivían entre los alumnos, orando juntos, trabajando unidos $y$, muchas veces, solucionando problemas propios de su entorno y de su comunidad estudiantil. Tal es el caso de la intervención del profeta Eliseo en el suceso del hacha hundida en el río (2 Reyes 6:1-7), (White, 1948, 5:14).

Se puede resumir entonces que la base de todos los procedimientos, 
las tareas, y las metas en esas "escuelas" de los jóvenes hebreos lo constituía el factor religioso y espiritual. Al respecto, White sostiene "el elemento religioso debe ser el poder controlador... la fuerza de nuestro colegio estriba en mantener el predominio del elemento religioso" (White, 1948, 5:14).

\section{Alumnos internos y externos}

No contamos con toda la información histórica, sin embargo, se puede inferir que algunos de los 'hijos de los profetas' residían en sus propios hogares. Tal es el caso relatado en 2 Reyes 4:1-8, donde se hace notar la historia de uno de los 'hijos de los profetas', casado, con hijos, y que vivió en su casa. Posiblemente otros alumnos también siguieron esta modalidad durante el período de su vida estudiantil.

Paralelamente, la Biblia presenta en 2 Reyes 6:1-7 la experiencia de los estudiantes ubicados en Jericó y que en cierto momento se dan cuenta que los ambientes de la comunidad resultaron insuficientes para el grupo, quienes expresaron "he aquí el lugar en que moramos contigo nos es estrecho" y decidieron hacer algo para solucionar aquella situación, contando con el apoyo de uno de sus maestros, en este caso, el del profeta Eliseo. Evidentemente, se trata de una residencia estudiantil bien establecida y que contaba con la visita o la compañía de uno de sus docentes.

Es posible que las compañías de profetas de Ramá y de Quiriat-Jearim se hayan desarrollado también en una especie de internados o residencias estudiantiles bajo la orientación de Samuel, su fundador, y que las de Gilgal, Betel y Jericó hayan seguido ese mismo estilo bajo la orientación del profeta Eliseo, quien "fue el supervisor de varias escuelas de los profetas, donde los jóvenes llamados al ministerio fueron entrenados y alentados" (Wiersbe, 2002).

\section{Currículo básico y general}

El currículo básico y columna vertebral de aquellas escuelas incluía como grandes áreas académicas: (a) las leyes de Dios, con las instrucciones dadas a Moisés; (b) la historia sagrada, porque "en los anales de la historia sagrada, se seguían los pasos de Jehová"; (c) la música sagrada y la poesía, por cuanto la música religiosa hebrea era empleada "con un propósito santo, para elevar los pensamientos hacia aquello que es puro, noble y enaltecedor, y para despertar en el alma la devoción y la gratitud hacia Dios" (White PP, 2005, 644). 
Complementando a aquellos dominios académicos estaban los estudios sobre profecías, escatología, la labranza de la tierra, el cuidado de los animales domésticos, el culto al verdadero Dios y el cuidado de la salud. Todos estos cursos apuntaban al gran propósito de todo estudio que era "aprender la voluntad de Dios y la obligación del hombre hacia él". Asimismo, a través de ellos "se recalcaban las grandes verdades presentadas por los símbolos o figuras y la fe trababa del objeto central de todo aquel sistema: el Cordero de Dios que había de quitar el pecado del mundo" (White PP, 2005, 644).

\section{Docentes consagrados}

Entre los varios maestros de las escuelas de los profetas destacaron tres por ser los más conocidos: Samuel, Elías y Eliseo. De ellos se afirma que, además de sus conocimientos y experiencia, gozaban del reconocimiento de la comunidad y la nación por su vida piadosa y su ejemplo. De estos se afirma que "eran hombres que no solo conocían la verdad divina, sino que habían gozado ellos mismos de la comunión con Dios, y habían recibido los dones especiales de su Espíritu. Gozaban del respeto y la confianza del pueblo, tanto por su saber como por su piedad" (White PP, 2005, 643), y que sus discípulos "se reunían alrededor de los grandes profetas como Samuel o Elías para adorar y orar juntos, así como para mantener la comunión religiosa e instruir al pueblo", (1 Samuel 10:5, 10; 2 Reyes 4:38, 40) (Nelson, 1998).

Al parecer, el profeta Eliseo fue uno de los más comprometidos con la educación y la formación de los jóvenes hebreos de su tiempo y por ende con el sistema que había empezado en los días de Samuel. Eliseo, además de la enseñanza y la consejería en aquellos centros, se dedicó también a la gestión y al desarrollo académico. En este sentido, White $(2005,195)$, aclara que "mientras Eliseo pudo viajar de lugar en lugar por todo el reino de Israel, continuó interesándose activamente en el fortalecimiento de las escuelas de los profetas".

Por otra parte, Eliseo ejercía también el don especial de sanidad, White (PP 2005, 181), traza un paralelismo entre su ministerio y el de Jesucristo. Ella reconoció el gran aporte de aquel siervo de Dios y declaró que "como el Salvador de la humanidad, al cual simbolizaba, Eliseo combinaba en su ministerio entre los hombres la obra de curación con la de la enseñanza. Con fidelidad e incansablemente, durante todas sus largas y eficaces labores, Eliseo se esforzó por hacer progresar la importante obra educativa que realizaban las escuelas de los profetas. 


\section{Estudiantes autofinanciados}

Es evidente que los alumnos de las escuelas de los profetas, mientras estudiaban se sustentaban básicamente mediante actividades agrícolas, de ganadería o de alguna otra índole práctica. En este sentido White (Ed, 2003, 43), opina que en aquellos días "los alumnos de estas escuelas se sostenían cultivando la tierra o realizando algún otro trabajo manual. En Israel no se consideraba cosa extraordinaria o degradante el trabajo; al contrario, se consideraba como pecado el permitir que los niños creciesen sin saber hacer trabajos útiles". De esta forma, el hecho de que un estudiante trabajara, además de estudiar, no solo contribuía a que fuera capaz de sustentar el costo de sus estudios, sino también que estaba participando de una parte fundamental de la filosofía de la educación hebrea, bíblica y profética, que era "promover el desarrollo del cuerpo, la mente y el alma... Este es el objeto de la educación" (Ed, 2003, 13).

La historia bíblica y la historia eclesiástica han mostrado que los maestros y líderes de entonces, a la vez que servían al Señor en sus diferentes tareas, también desarrollaban otras actividades para autosostenerse. En este sentido, White (Ed, 2005, 644), afirma que "muchos de los maestros religiosos se sostenían por el trabajo de sus manos. Aun en el tiempo de los apóstoles, Pablo y Aquila no veían menoscabado su honor porque se ganaban la vida ejerciendo su oficio de tejedores de tiendas".

\section{Conclusión}

En síntesis, cada maestro y trabajador del área educativa sea cristiano o no cristiano debe reflexionar acerca de lo que significan aquellas escuelas de los profetas. Más aún, sería pertinente tratar de fortalecernos con la visión y la misión que motivó a las mismas. Sería de sabios tratar de seguir las huellas que nos dejaron.

Qué hermoso sería observar el mismo espíritu de devoción y cristianismo profundo de las escuelas de los profetas en nuestros maestros y alumnos. Qué bien haría tratar de implementar la combinación de estudio y trabajo como una característica distintiva de la formación de cada estudiante, aunque no la necesitara para sufragar sus costos. Y qué maravilloso sería tratar de brindar una atención tutorial más personalizada para cada alumno de las instituciones educativas. 
Por otro lado, sería oportuno revisar el contenido de los currículos académicos buscando fortalecer y consolidar la filosofía de la educación cristiana, robustecer las materias bíblicas formativas, la enseñanza y práctica de valores cristianos y el énfasis misionero permanente por precepto y ejemplo que diferencian a las instituciones cristianas de otras instituciones que siguen filosofías educativas seculares.

Obviamente, conducir el sistema educativo ideal no es fácil. Así como en los tiempos bíblicos fueron necesarios grandes y consagrados hombres de Dios como Samuel, Elías, Eliseo y otros, también hoy se requiere de líderes idóneos como aquellos. Animamos a que cada docente y trabajador educativo se consagre al Maestro de los maestros, buscando el bautismo diario de su Santo Espíritu (Filipenses 4:13), porque "a medida que el que trabaja se entrega sin reserva al servicio del Señor, adquiere una experiencia que le capacita para trabajar cada vez con más éxito para el Señor". (White, JT 1965).

Cuanto más de cerca se siga el modelo y la filosofía educativa cristiana, mayores bendiciones vendrán del Dios que creó este sistema. 


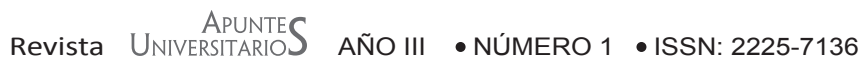

\section{Referencias}

Diez Macho, A. (1963). Enciclopedia de la Biblia. Vol. 5. Barcelona: Ediciones Garriga,

Gaebelein, A. (2009). The Annotated Bible, Joshua to Second Chronicles, Vol. 2: Bellingham, WA: Logos Research Systems, Inc.

Nelson, W., Rojas J. (2000). Nelson, Nuevo Diccionario Ilustrado De La Biblia, electronic ed. Nashville: Editorial Caribe.

Nichol, F. (1980). Comentario Bíblico Adventista del Séptimo Día. Tomo 2. Idaho: Publicaciones Interamericanas.

Walvoord, J., Zuck, R. (1983). The Bible Knowledge Commentary : An Exposition of the Scriptures. Wheaton, IL: Victor Books.

White, E. (1948) Joyas de los testimonios, vol. 5. Nampa, Idaho: Pacific Press Publishing Association.

White, E. (2005). Patriarcas y Profetas. Buenos Aires: Asociación Casa Editora Sudamericana.

White, E. (2000). Profetas y Reyes. Buenos Aires: Asociación Casa Editora Sudamericana.

White, E. (2003). La Educación. Buenos Aires: Asociación Casa Editora Sudamericana.

Wiersbe, W. (2002). Be Distinct. Colorado Springs, Colo.: Victor.

Wolfgramm, A. (1990). Kings, The People's Bible. Milwaukee, Wis.: Northwestern Publish House. 